\title{
Dental anomalies in the deciduous dentition of non-syndromic oral clefts patients
}

Adriana Boeri Freire Tamburini 1

iD https://orcid.org/0000-0002-0153-3875

Ygor Henrique Pereira Rodrigues 2

iD https://orcid.org/0000-0003-1365-7610

Daniella Reis Barbosa Martelli 3

iD https://orcid.org/0000-0002-7497-6052

Letízia Monteiro de Barros 4

(iD) https://orcid.org/0000-0002-5181-6224

Rodrigo Soares de Andrade 5

iD https://orcid.org/0000-0001-6114-0929

\author{
Renato Assis Machado 6 \\ (iD) https://orcid.org/0000-0002-1697-3662 \\ Ricardo Della Coletta 7 \\ (iD) https://orcid.org/0000-0001-5285-3046 \\ Hercílio Martelli-Júnior 8 \\ D https://orcid.org/0000-0001-9691-2802 \\ Flávia Martão Flório 9 \\ D https://orcid.org/0000-0001-7742-0255
}

\footnotetext{
1,2,4 Center for Rehabilitation of Craniofacial Anomalies. Dental School. University of José RosárioVellano. Algenas, MG, Brazil.

3,8 Stomatology Clinic, Dental School. State University of Montes Claros. Montes Claros, MG, Brazil.

5,6,7 Department of Oral Diagnosis, Dental School. University of Campinas. Av. Limeira, 901. Piracicaba, SP, Brazil. CEP: 13.414-903. E-mail: rodrigosoares002@hotmail.com

9 Department of Social and Preventive Dentistry, São Leopoldo Mandic Institute and Dental Research Center. Campinas, SP, Brazil.
}

\begin{abstract}
Objectives: to investigate the prevalence of dental anomalies in complete deciduous dentition of children with NSCL/P.

Methods: this study included 75 children with NSCL/P and 286 healthy control. In both groups the children had deciduous dentition with ages varying from 4 to 6 years. Clinical examination, panoramic and periapical radiographies were performed and dental anomalies of number and shape were considered.

Results: there was a higher prevalence of dental anomalies in the case group, compared to the control group. In all, 42 dental anomalies were identified, 25.33\% in the case group and $8.04 \%$ in control group $(p<0.001)$. Therewas a higher frequency of dental anomalies in NSCL/P (47.36\%), followed by non-syndromic cleft lip (31.57\%) and non-syndromic cleft palate $(21.05 \%)$. The occurrence of agenesis $(p=0.005)$ and twinning $(p=0.029)$ were higher in the case group.

Conclusions: the occurrence of agenesis and dental twinning was more frequent in the case group and may contribute to the definition of oral cleft subphenotype.

Key words Cleft lip, Cleft palate, Dental abnormalities, Primary dentition, Teeth agenesis, Dental twinning
\end{abstract}




\section{Introduction}

Oral clefts are the most common orofacial birth defect, occurring in 1 in 500-2,500 live births worldwide. ${ }^{1}$ In Brazil, the prevalence varies from 0.36 to 1.54 per 1,000 live births. ${ }^{2,3}$ About $70 \%$ of cases occur as a non-syndromic form [non-syndromic cleft lip and/or cleft palate (NSCL/P)], and the remaining $30 \%$ are associated with Mendelian disorders or chromosomal, teratogenic and sporadic conditions. ${ }^{4}$ Based on epidemiological features and embryologic timing, NSCL/P are traditionally divided in cleft lip $(\mathrm{CL})$, cleft lip and palate $(\mathrm{CL} / \mathrm{P})$ and cleft palate (CP). ${ }^{5}$ The etiology of NSCL/P is attributed to an interplay of genetic and environmental factors, but the exact interactions are poorly known. 1

Studies proposed that dental anomalies could serve as clinical markers for defining cleft subphenotypes, suggesting a common genetic background between those conditions. ${ }^{6}$ In favor of this hypothesis is that tooth, lip and palate development occur almost concomitantly and are related anatomically.7,8

When compared to the general population, dental anomalies, such as tooth agenesis, supernumerary tooth, microdontia, fused tooth, ectopic eruption, rotation of teeth, taurodontism and enamel hypoplasia, are considerably more prevalent in individuals with CP.6,7,9,10,11 Interestingly, few studies have investigated the frequency of dental anomalies in the primary dentition of patients with CL/P.12,13

Thus, the aim of the current study was to investigate the prevalence of dental anomalies in the complete primary dentition in a group of Brazilian children with NSCL/P.

\section{Methods}

This cross-sectional, observational, case-control study included 75 children with NSCL/P (case group) and 286 healthy control group. All cases were recruited at the Centro de Reabilitação de Anomalias Craniofaciais (Rehabilitation Center for Craniofacial Anomalies) in Minas Gerais, Brazil and the control group was randomly obtained at the Pediatric Dentistry Clinic at the University. Patients were recruited during 2016 and until 2017, and in both groups, the children had completed primary dentition with ages varying from 4 to 6 years. All patients with NSCL/P were carefully evaluated by experts at the Rehabilitation Center.

In both study groups, the subjects were selected by convenience from all the patients that were assisted at the Center, between 2016 and 2017. The control group was composed of healthy individuals with no physical illness, psychiatric, birth defects or with a family history of orofacial clefts. All the subjects were from Minas Gerais, Brazil, where there is an admixed population of Europeans (mostly from Portugal and Italy) and Africans, with a small percentage of native Brazilian Indians. ${ }^{14}$ All the patients presented similar ethnicities and social culture and were assisted by the Brazilian Sistema Unico de Saúde (SUS) (Public Health System).

The oral clefts were categorized into three incisive groups as a reference: Cleft Lip (CL): includes complete or incomplete clefts, either unilateral or bilateral; Cleft Lip and Palate $(\mathrm{CL} / \mathrm{P})$ : includes unilateral or bilateral clefts; Cleft Palate (CP): includes all complete, or incomplete clefts. 15

For both groups, clinical exam and panoramic and periapical radiographs were performed. Only dental anomalies of a dental shape (fusion, twinning, taurodontism, dens invaginatus, dens evaginatus, dilaceration, microdontia, macrodontia, third root and conidial tooth) and number (agenesis and supernumerary teeth) considered in this study, and only those outside the cleft area were included. The classification of the dental anomalies was previously performed as described. In order to eliminate examiner differences, dental anomalies were classified by a single examiner (ABFT).

The information collected was stored in a database and analysed using the statistical program SPSS ${ }^{\circledR}$ version 19.0 (Statistical Package for Social Sciences for Windows, Inc., USA). The comparisons were assessed by a cross-tabulation of the chi-square test, and statistical significance was set at $p<0.05$. The odds ratios (OR) were estimated with a $95 \%$ confidence interval.

This study was approved by the Ethics Committee in Research at the University (document number: 1.612.095). A written informed consent was obtained from the parents or guardians and/or the participants.

\section{Results}

Of the 361 subjects included in this study, 180 were males and 181 were females. In the case group $(n=75), 43$ were males and 32 were females, while in the control group $(n=286), 137$ were males and 149 were females. Of the 75 patients with oral clefts, the majority $(\mathrm{n}=38 ; 50.66 \%)$ was affected by NSCL/P, followed by CP $(n=20 ; 26.66 \%)$ and $C L(n=17$; $22.66 \%)$. There was a higher proportion of cases $(9.33 \%)$ with family history of NSCL/P compared to the control $(1.39 \%)(p=0.002)$. 
Thirty-nine (10.80\%) patients from both groups had dental anomalies, 16 patients $(21.33 \%)$ belonged in the case group, and $23(8.04 \%)$ in the control group. Table 1 presents the types of dental anomalies distributed in both groups. Altogether, 42 dental anomalies were identified, $25.33 \%(\mathrm{n}=19)$ in the case group and $8.04 \%(\mathrm{n}=23)$ in the control $(p<0.001)$. The most common anomaly was the supernumerary teeth $(\mathrm{n}=14)$ in both study groups ( $p=0.160$ ), followed by dental agenesis and fusion, both with 6 occurrences. Dental agenesis $(p=0.005)$ and twinning ( $p=0.029)$ were more common in the case group comparing to the control group.

In regards to the distribution of dental anomalies and the type of oral cleft, it was observed that there was a higher prevalenceamong patients with NSCL/P ( $n=9 ; 47.36 \%)$, followed by CL $(n=6$; $31.75 \%)$ and $\mathrm{CP}(\mathrm{n}=4 ; 21.05 \%)$. Of 4 cases of dental agenesis, 3 occurred in NSCL/P and 1 in $\mathrm{CP}$, while, of the 3 cases of twinning, 2 occurred in NSCL/P and $1 \mathrm{CL}$.

Regarding to the 42 dental anomalies identified, $57.14 \%(\mathrm{n}=24)$ occurred in the superior maxillary arch and $42.85 \%(n=18)$ in the mandibular arch. Most of the dental anomalies involved the lateral incisor $(\mathrm{n}=15 ; 35.71 \%)$ and the central incisor $(n=14 ; 33.33 \%)$. As for the laterality of the clefts, 25 $(59.52 \%)$ occurred on the right side and 17 (40.47\%) on the left side (Table 2 and 3 ).

\section{Discussion}

In this case-control study, we investigated the prevalence of dental anomalies in the complete primary dentition of patients with NSCL/P. Our results showed that the prevalence was higher in the case group, compared to control group. Among the dental anomalies, supernumerary teeth were the most frequently observed in both study groups (14 cases). In the NSCL/P group, all the supernumerary teeth occurred in the maxilla $(n=5)$, while in the control group the distribution was similar between the maxilla and mandible $(n=9)$. However, this dental anomaly did not present any differences in the frequency between the groups.

In a retrospective analysis of 207 panoramic radiographies of Brazilian patients with NSCL/P aged 12 to 45 years old, found that the frequency of supernumerary teeth was higher in patients with complete bilateral NSCL/P. 16 In another study evaluating dental anomalies of NSCL/P, did not find a significant increase of supernumerary teeth compared to the general population. ${ }^{7}$

Recently, in a longitudinal study, Suzuki et al.17 found that the prevalence of tooth agenesis was $16.2 \%$ for primary dentition and $52.7 \%$ for permanent dentition in subjects with NSCL/P. In a previous study, it was verified that the occurrence of tooth agenesis was $22.3 \%$ in the permanent dentition of subjects with oral clefts. ${ }^{7}$ This number is in agreement with various studies that found percentages of tooth agenesis around $24 \%$ outside the cleft area, $6,16,18,19$ confirming tooth agenesis is almost five times more common in individuals with cleft than in the general population (4.83\%).20 In another study, involving 60 children between 5 and 13 years with NSCL/P, the occurrence of tooth agenesis was $63.3 \% .21$

The distribution of tooth agenesis was significantly higher in the case group and between patients with NSCL/P. Most studies have shown that NSCL/P has the highest prevalence of tooth agenesis.17,22 In our study, in the case group, the teeth involved by agenesis were mainly the lateral incisors and second molar. In general, previous studies have reported that anomalies, such as tooth agenesis, in these teeth are the most common findings in children with CL/P. $6,15,17,22$

Twinning is defined as incomplete development of two teeth from one enamel organ. Tooth twinning was another dental anomaly prevalent in the group with CL/P $(p=0.029)$. Aizenbud et al.23 in one study including 657 cleft lip patients, where 19 were children aged from 9-13 years old were treated during the last 10 years, observed the highest occurrence of dental twinning compared to the general population. Our results are consistent with this study, showing the highest occurrence of twinning between the NSCL/P. Also was observed a higher occurrence of dental twinning between the lateral incisors, similar to those found in the permanent dentition. ${ }^{24}$ All the other dental anomalies, fusion $(p=0.445)$, microdontia $(p=0.147)$, talon cusps $(p=0.590)$ and third root $(p=0.147)$ did not present differences between the case and the control groups.

In our study, there was a higher proportion of cases $(9.33 \%)$ with family history of NSCL/P compared to the control group $(1.39 \%)(p=0.002)$. In a previous study performed by our group, a positive family history of NSCL/P was found in $35.13 \%$ of cases. 25

A study investigated 4,557 affected children born in the Czech Republic of Slovakia over a period of 29 years, registered a positive family history in $18 \%$ of the cases. ${ }^{26}$ In the sixth study comprised of 153 individuals with NSCL/P in Thailand, registered a positive family history in $17.7 \%$ of the cases. 27

The occurrence of dental anomalies showed no 
Table 1

Distribution of dental anomalies in the case (non-syndromic oral clefts) and the control groups.

\begin{tabular}{|c|c|c|c|c|c|c|}
\hline \multirow[t]{2}{*}{ Dental anomaly } & \multicolumn{2}{|c|}{$\begin{array}{l}\text { Case group } \\
\qquad(\mathrm{N}=75)\end{array}$} & \multicolumn{2}{|c|}{$\begin{array}{l}\text { Control group } \\
\qquad(\mathrm{N}=286)\end{array}$} & \multirow[t]{2}{*}{$p$} & \multirow[t]{2}{*}{ OR } \\
\hline & $\mathrm{n}$ & $\%$ & $\mathrm{n}$ & $\%$ & & \\
\hline Agenesis & 4 & 21.05 & 2 & 8.69 & 0.005 & $3.33(1.82-6.09)$ \\
\hline Fusion & 2 & 10.52 & 4 & 17.39 & 0.445 & $1.62(0.51-5.11)$ \\
\hline Twinning & 3 & 15.78 & 2 & 8.69 & 0.029 & $2.96(1.40-6.24)$ \\
\hline Microdontia & 2 & 10.52 & 2 & 8.69 & 0.147 & $2.44(0.89-6.65)$ \\
\hline Supernumerary & 5 & 26.31 & 9 & 39.13 & 0.160 & $1.77(0.85-3.68)$ \\
\hline Talon cusps & 1 & 5.26 & 2 & 8.69 & 0.590 & $1.61(0.32-8.05)$ \\
\hline Third root & 2 & 10.52 & 2 & 8.69 & 0.147 & $2.44(0.89-6.65)$ \\
\hline Total & 19 & 100.0 & 23 & 100.0 & & \\
\hline
\end{tabular}

Table 2

Distribution of dental anomalies in the maxillary arch of the case (non-syndromic oral clefts) and the control groups.

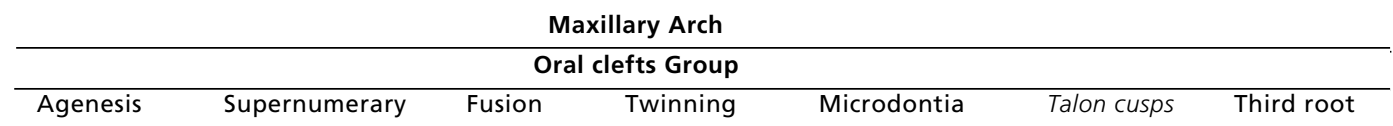

\begin{tabular}{|c|c|c|c|c|c|c|c|c|c|c|c|c|c|c|}
\hline Tooth & $R$ & $L$ & $R$ & $L$ & $R$ & $L$ & $R$ & $L$ & $R$ & $L$ & $R$ & $L$ & $R$ & $L$ \\
\hline \multicolumn{15}{|c|}{ Primary dentition } \\
\hline Central incisor & 0 & 0 & 0 & 1 & 0 & 0 & 0 & 0 & 1 & 0 & 0 & 0 & 0 & 0 \\
\hline Lateral incisor & 0 & 2 & 1 & 1 & 0 & 1 & 2 & 0 & 0 & 0 & 0 & 0 & 0 & 0 \\
\hline Canine & 0 & 0 & 1 & 1 & 0 & 0 & 0 & 1 & 0 & 0 & 0 & 0 & 0 & 0 \\
\hline 1st molar & 0 & 0 & 0 & 0 & 0 & 0 & 0 & 0 & 0 & 0 & 0 & 0 & 0 & 0 \\
\hline 2nd molar & 0 & 0 & 0 & 0 & 0 & 0 & 0 & 0 & 0 & 0 & 1 & 0 & 0 & 0 \\
\hline
\end{tabular}

\section{Control Group}

\begin{tabular}{lllllllllllllll} 
Central incisor & 0 & 0 & 2 & 2 & 1 & 0 & 0 & 0 & 1 & 0 & 0 & 0 & 0 & 0 \\
Lateral incisor & 0 & 0 & 0 & 0 & 1 & 0 & 1 & 0 & 0 & 0 & 0 & 0 & 0 & 0 \\
Canine & 0 & 0 & 0 & 1 & 0 & 0 & 0 & 0 & 0 & 0 & 0 & 0 & 0 & 0 \\
1st molar & 0 & 0 & 0 & 0 & 0 & 0 & 0 & 0 & 0 & 0 & 0 & 1 \\
2nd molar & 0 & 0 & 0 & 0 & 0 & 0 & 0 & 0 & 0 & 0 & 1 & 0 \\
\hline
\end{tabular}

Right (R) and Left (L). 
Distribution of dental anomalies in the mandibular arch of the case (non-syndromic oral clefts) and the control groups.

\begin{tabular}{|c|c|c|c|c|c|c|c|c|c|c|c|c|c|c|}
\hline \multirow[b]{4}{*}{ Tooth } & \multicolumn{12}{|c|}{ Maxillary Arch } & & \\
\hline & \multicolumn{12}{|c|}{ Oral clefts Group } & & \\
\hline & \multicolumn{2}{|c|}{ Agenesis } & \multicolumn{2}{|c|}{ Supernumerary } & \multicolumn{2}{|c|}{ Fusion } & \multicolumn{2}{|c|}{ Twinning } & \multicolumn{2}{|c|}{ Microdontia } & \multicolumn{2}{|c|}{ Talon cusps } & \multicolumn{2}{|c|}{ Third root } \\
\hline & $R$ & $L$ & $R$ & $L$ & $R$ & $L$ & $R$ & $L$ & $R$ & $L$ & $R$ & $L$ & $R$ & $L$ \\
\hline \multicolumn{15}{|c|}{ Primary dentition } \\
\hline Central incisor & 0 & 0 & 0 & 0 & 0 & 0 & 0 & 0 & 0 & 0 & 0 & 0 & 0 & 0 \\
\hline Lateral incisor & 1 & 0 & 0 & 0 & 1 & 0 & 0 & 0 & 0 & 1 & 0 & 0 & 0 & 0 \\
\hline Canine & 0 & 0 & 0 & 0 & 0 & 0 & 0 & 0 & 0 & 0 & 0 & 0 & 0 & 0 \\
\hline $1^{\text {st }}$ molar & 0 & 0 & 0 & 0 & 0 & 0 & 0 & 0 & 0 & 0 & 0 & 0 & 2 & 0 \\
\hline $2^{\text {nd }}$ molar & 1 & 0 & 0 & 0 & 0 & 0 & 0 & 0 & 0 & 0 & 0 & 0 & 0 & 0 \\
\hline
\end{tabular}

Control Group

$\begin{array}{lllllllllllllllll}\text { Central incisor } & 1 & 0 & 1 & 2 & 0 & 1 & 0 & 1 & 0 & 0 & 0 & 0 & 0 & 0 \\ \text { Lateral incisor } & 0 & 0 & 1 & 0 & 1 & 0 & 0 & 0 & 0 & 1 & 0 & 0 & 0 & 0 \\ \text { Canine } & 1 & 0 & 0 & 0 & 0 & 0 & 0 & 0 & 0 & 0 & 0 & 0 & 0 & 0 \\ \text { 1st molar } & 0 & 0 & 0 & 0 & 0 & 0 & 0 & 0 & 0 & 0 & 0 & 0 & 0 & 0 \\ \text { 2nd molar } & 0 & 0 & 0 & 0 & 0 & 0 & 0 & 0 & 0 & 0 & 0\end{array}$

Right (R) and Left (L).

significant differences between the maxilla and the mandible. Although the occurrence of dental anomalies could be explained as a consequence of plastic surgery to repair the oral clefts, which can affect the development of maxillary bone resulting in less space in the superior arch for normal eruption of the teeth, it is interesting to mention that the higher incidence of dental anomaly occurred in the mandible.6,28 Oral clefts show evidence of directional laterality, with left-sided clefts occurring about twice as often as the right-sided clefts. ${ }^{29}$ Such asymmetry is common in other aspects of embryonic development, including medical and academic outcomes. ${ }^{30}$ Although with a limited population, our study showed an increase on the occurrence of $\mathrm{NSCL} / \mathrm{P}$ on the right side.

In conclusion, our results suggest that there is a higher prevalence of dental abnormalities in the complete primary dentition of individuals with oral clefts, compared to the general population. The occurrence of tooth agenesis and twinning were significant in the group with NSCL/P and may contributeto define oral clefts subphenotypes. However, further studies are required to validate our findings. The limitation of this study was the population sample size used.

\section{Acknowledgments}

We thank the Fundação de Pesquisa do Estado de Minas Gerais (FAPEMIG) and Conselho Nacional de Desenvolvimento Científico e Tecnológico (CNPq) by financial support.

\section{Authors' contribution}

Tamburini ABF designed and developed the manuscript. Rodrigues YHP and Barros LM participated in the data collection. Martelli DRB performed the statistical tests. Andrade RS formatted and adapted the text. Machado RA and Coletta RD reviewed the text. Martelli-Jr H and Flório FM oriented the production, data collection and writing of the text. All authors approved the final version of the article. 


\section{References}

1. Dixon MJ, Marazita ML, Beaty TH, Murray JC. Cleft lip and palate: understanding genetic and environmental influences. Nat Rev Genet. 2011; 12 (3): 167-78.

2. Martelli-Junior H, Porto LV, Martelli DR, Bonan PR, Freitas AB, Della Coletta R. Prevalence of nonsyndromic oral clefts in a reference hospital in the state of Minas Gerais, Brazil, between 2000-2005. Braz Oral Res. 2007; 21 (4): 314-7.

3. Rodrigues K, Sena MF, Roncalli AG, Ferreira MA Prevalence of orofacial clefts and social factors in Brazil. Braz Oral Res. 2009; 23 (1): 38-42.

4. Meng L, Bian Z, Torensma R, Von denHoff JW. Biological mechanisms in palatogenesis and cleft palate. J Dent Res. 2009; 88 (1): 22-33.

5. Machado RA, Freitas EM, Aquino SN, Martelli DRB, Swerts MSO, Reis SR, Persuhn DC, Moreira HS, Dias VO, Coletta RD, Martelli Júnior H. Clinical relevance of breast and gastric cancer-associated polymorphisms as potential susceptibility markers for oral clefts in the Brazilian population. BMC Med Genet. 2017; 4 (1): 1-6.

6. Letra A, Menezes R, Granjeiro JM, Vieira AR. Defining subphenotypes for oral clefts based on dental development. J Dent Res. 2007; 86 (10): 986-91.

7. Paranaíba LMR, Coletta RD, Swerts MSO. Quintino RP, Barros LM, Martelli-Júnior H. Prevalence of dental anomalies in patients with nonsyndromic cleft lip and/or palate in a Brazilian population. Cleft Palate-Craniofac J. 2013; 50 (4): 400-5.

8. Schutte BC, Murray JC. The many faces and factors of orofacial clefts. Hum Mol Genet. 1999; 89 (10): 1853-9.

9. Melo Filho MR, Dias VO, Martelli DRB, Paranaíba LMR, Swerts MSO, Barros LM. Tooth malposition in patients with cleft lip and/or palate in a Brazilian population. Dentistry. 3000. 2015; 3 (6): 1-6.

10. Mangione F, Nguyen L, Foumou N, Bocquet E, Dursun E. Cleft palate with/without cleft lip in French children: radiographic evaluation of prevalence, location and coexistence of dental anomalies inside and outside cleft region. Clin Oral Investig. 2017; 22 (2): 689-95.

11. Kuchler E, Motta L, Vieira A, Granjeiro J. Side of dental anomalies and taurodontism as potential clinical markers for cleft subphenotypes. Cleft Palate-Craniofac J. 2011; 48 (1):103-8.

12. Pegelow M, Alqadi N, Karsten A. The prevalence of various dental characteristics in the primary and mixed dentition in patients born with non-syndromic unilateral cleft lip with or without cleft palate. Eur. J. Orthod. 2012; 3(34):561-570.

13. Sæle P, Østhus E2, Ådalen S, Nasir EF, Mustafa M. Pattern of clefts and dental anomalies in six-year-old children: a retrospective observational study in western Norway. Acta Odontol Scand. 2017; 75 (2): 100-5

14. Aquino SN, Messetti AC, Bagordakis E, Martelli Júnior H, Swerts MSO, Graner E, Coletta RD. Polymorphisms in FGF12, VCL, CX43 and VAX1 in Brazilian patients with nonsyndromic cleft lip with or without cleft palate. BMC Med Genet. 2013; 2 (14): 53-7.
15. Spina V, Psillakis JM, Lapa FS, Ferreira MC. Classification of cleft lip and cleft palate. Suggested changes. Rev Hosp Clin Fac Med São Paulo. 1972; 27 (1): 5-6.

16. Sá J, Mariano LC, Canguçu D, Coutinho TSL, Hoshi R, Medrado AP Martelli-Junior H, Coletta RD, Reis SRA. Dental Anomalies in a Brazilian Cleft Population. Cleft Palate-Craniofac J. 2016; 53 (6): 714-9.

17. Suzuki A, Nakano M, Yoshizaki K, Yasunaga A, Haruyama N, Takahashi I. A Longitudinal Study of the Presence of Dental Anomalies in the Primary and Permanent Dentitions of Cleft Lip and/or Palate Patients. Cleft Palate-Craniofac J. 2016; 54 (3): 309-20.

18. Silva AP, Costa B, de Carvalho Carrara CF. Dental anomalies of number in the permanent dentition of patients with bilateral cleft lip: radiographic study. Cleft PalateCraniofac J. 2008; 45 (5): 473-6.

19. Menezes R, Vieira AR. Dental anomalies as part of the cleft spectrum. Cleft Palate Craniofac J. 2008; 45(4): 414-419.

20. Polder BJ, Van't Hof V MA, Van der Linden FPGM, Kuijpers-Jagtma AM. A meta-analysis of the prevalence of dental agenesis of permanent teeth. Community Dent Oral Epidemiol. 2004; 32 (3): 217-26.

21. Tan ELY, Kuek MC, Wong HC, Ong SAK, Yow M. Secondary Dentition Characteristics in Children With Nonsyndromic Unilateral Cleft Lip and Palate: A Retrospective Study. Cleft Palate-Craniofac J. 2018; 55 (4): 582-9.

22. Tsai TP, Huang CS, Huang CC, See LC. Distribution patterns of primary and permanent dentition in children with unilateral complete cleft lip and palate. Cleft PalateCraniofac J. 1998; 35 (2): 154-60.

23. Aizenbud D, Coval M, Hazan-Molina H, Harari D. Isolated soft tissue cleft lip: epidemiology and associated dental anomalies. Oral Dis. 2011; 17 (2): 221-31.

24. Al Jamal GA, Hazza'a AM, Rawashdeh MA. Prevalence of dental anomalies in a population of cleft lip and palate patients. Cleft Palate-Craniofac J. 2010; 47 (4): 413-20.

25. Martelli DR, Bonan PR, Soares MC, Paranaíba LR, Martelli-Júnior H. Analysis of familial incidence of nonsyndromic cleft lip and palate in a Brazilian population. Med Oral Patol Oral Cir Bucal. 2010; 15 (6): 898-901.

26. Peterka M, Peterkova R, Halaskova M, Tvrdek M, Fara M, Likovsky Z. Sex differences in the incidence of cleft and question of primary prevention in families with genetic risk. Acta Chir Plast. 1996; 38 (2): 57-60.

27. Jaruratanasirikul S, Chichareon V, Pattanapreechawong N, Sangsupavanich P. Cleft lip and/or palate: 10 years experience at a pediatric cleft center in Southern Thailand. Cleft Palate-Craniofac J. 2008; 45 (6): 597-602.

28. Genisca AE, Frias JL, Broussard CS, Honein MA, Lammer EJ, Moore CA, Rasmussen SA. Orofacial clefts in the national birth defects prevention study. Am J Med Genet. 2009; 149 (6): 1149-58

29. Melo Filho MR, Santos LAN, Martelli DRB, Silveira MF, Silva ME, Barros LM, Coletta RD, Martelli-Júnior H. Taurodontism in patients with nonsyndromic cleft lip and 
palate in a Brazilian population: a case control evaluation with panoramic radiographs. Oral Surg Oral Med Oral Pathol Oral Radiol. 2015; 120 (6): 744-50.

30. Gallagher ER, Siebold B, Collett BR, Cox TC, Aziz V, Cunningham ML. Associations between laterality of orofacial clefts and medical and academic outcomes. Am J Med Genet. 2017; 3 (2): 1-10.

Received on January 30, 2019

Final version presented on July 14, 2019

Approved on December 23, 2019 